\section{Complex and unique}

\section{HIV/AIDS epidemic among}

\section{Aboriginal Canadians}

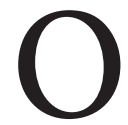

pportunistic infections that were the hallmark of the early days of the AIDS epidemic in Canada - PCP, MAC, CMV and meningitis - are conditions that nurse Doreen Littlejohn sees regularly at the Vancouver Native Health Society.

These infections - Pneumocystis carinii pneumonia, Mycobacterium avium complex and cytomegalovirus are rarely seen now among, for example, male homosexuals who still make up the majority of Canadians living with HIV, observes Mark Tyndall, an HIV/AIDS researcher at the British Columbia Centre of Excellence in HIV/AIDS.

But among the population served by Littlejohn, people are routinely diagnosed late, when their $\mathrm{CD}_{4}$ counts are low and their viral load high. "We try to stabilize them as much as possible," with primary health care and other services, says Littlejohn who runs the society's Positive Outlook Program, which sees up to 200 people a day, 7 days a week. "Then we talk to them about starting a treatment regimen."

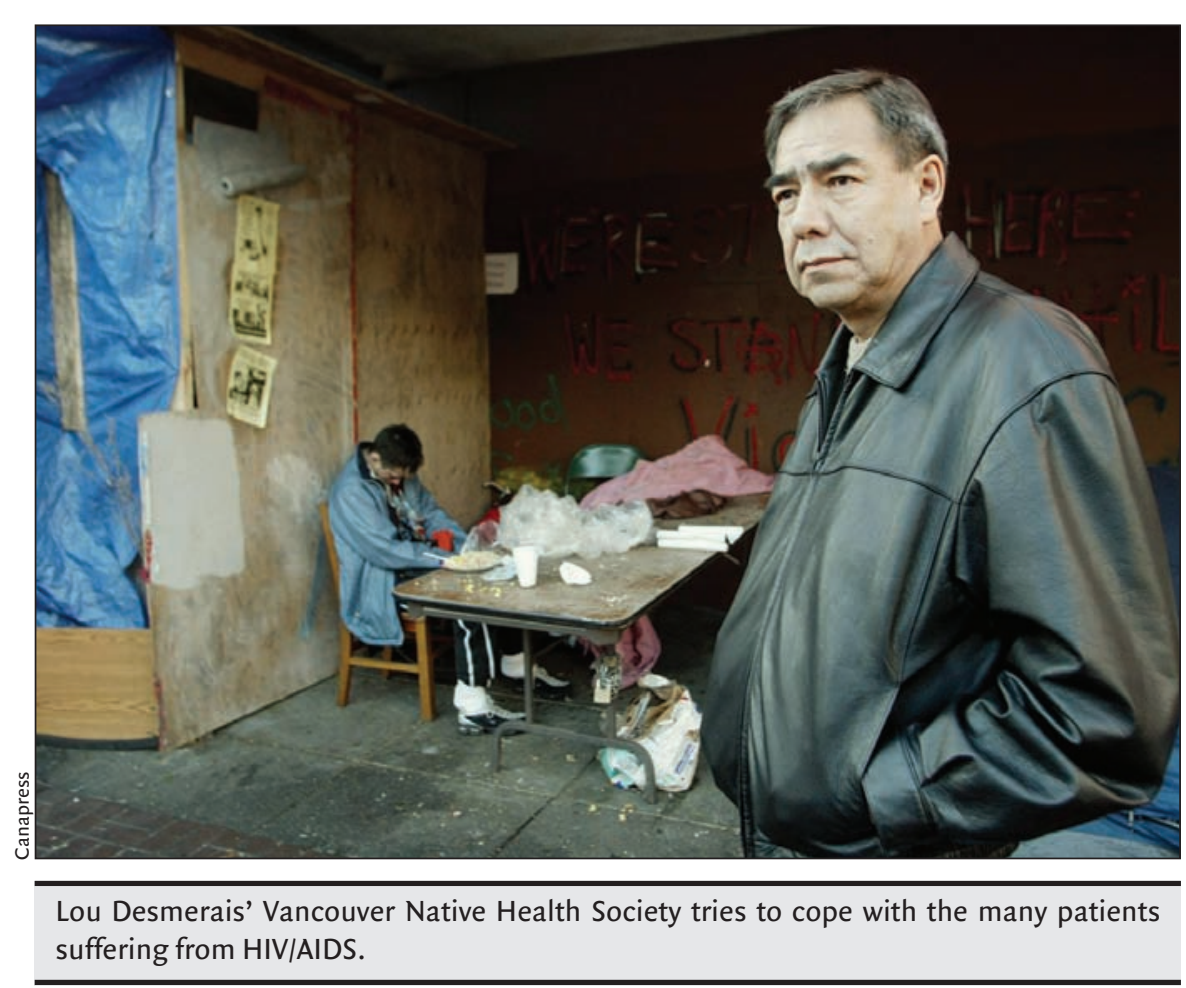

Lou Desmerais' Vancouver Native Health Society tries to cope with the many patients suffering from HIV/AIDS.

The unique and complex nature of the HIV/AIDS epidemic among Aboriginal Canadians is reflected in statistics that show the population has a far higher proportion of new HIV infections caused by injection drug use ( $53 \%$, compared to $14 \%$ among nonAboriginals) and among women (about $45 \%$ compared to $20 \%$ ).

Meanwhile, researchers are warning that there is potential for explosive outbreaks of HIV among young, injection drug using Aboriginals. A study of drugusing Aboriginal youth in Vancouver and Prince George has found high rates of hepatitis C infection $(57 \%$ and $62 \%$, respectively), which is also passed through needle sharing. About half the youth, whose average age is 23 , are injection drug users, and the HIV prevalence among the entire group is now $8 \%$.

Around the world there have been situations among illicit injection drug users where HIV "suddenly goes from low to high prevalence - to $30 \%$ to $40 \%$ - in a year or 2 " as happened in Vancouver's Downtown Eastside in I996 and I997, says Dr. Martin Schechter, an epidemiologist and coinvestigator of the Cedar Project.

All the ingredients for such an outbreak exist in Prince George, where the risks include more cocaine injection, which involves more frequent needle use than heroin, and less access to care than in Vancouver, warns principal investigator Patricia Spittal. About 50\% of the youth in the study group are female, and many are involved in the sex trade, she said.

"This is more than a big city issue ... and man, this thing is moving," notes Spittal. Proven harm reduction strategies - such as very accessible needle exchanges and mobile health care vans to help sex workers - need to be introduced in smaller centres, she argues.

Treating HIV among people with addiction problems and who may be homeless or living in marginalized conditions is challenging. Littlejohn's program offers what it calls "maximally assisted therapy" (MAT), in which HIV medications are kept on site and dispensed to clients at the centre. "We have to work with their comfort level; MAT can be viewed as paternalistic. We try to address all the determinants of health."

Spittal also sees some hope in the growing acceptance of communitybased research, where researchers work with the community, as has been spearheaded by the Institute for Aboriginal Peoples' Health. "The innovations are going to come at the community level, that is how you are going to get better designed programs." - Ann Silversides, Toronto

DOI:I0.1503/cmaj.061349

\section{HIV prophylaxis expensive}

\section{and sometimes difficult to}

\section{obtain}

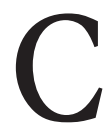

anadians seeking help after being accidentally exposed to HIV through a sexual encounter can meet with a range of unhelpful responses and no clear policies.

Yet, if a month-long course of antiHIV medication is initiated within 72 hours of exposure, evidence from a key study of occupational exposure among health workers indicates that infection can be prevented in most cases (MMWR 1995;44). It can also cost up to \$1500. 